Терзиев Венелин Кръстев

доктор экономических наук, доктор военных наук доктор философских наук, профессор Русенского университета им. Ангела Кънчева, профессор Национального военного университета им. Васила Левского, Велико Тырново, член-корреспондент Российской академии естественных наук

\section{ВЗАИМОДЕЙСТВИЕ СОЦИАЛЬНЫХ ПРЕДПРИЯТИЙ И ГОСУДАРСТВА В БОЛГАРИИ}

Аннотация:

В статье рассматриваются социальные предприя тия и социальное предпринимательство как при мер устойчивой бизнес-модели, ориентированной на достижение как социальных, так и экономических целей. Проанализированы различные типы социальных предприятий Болгарии, предоставляющие социальные, медицинские, образовательные услуги, приведены основные характеристики их деятельности. Раскрыто содержание понятия «социальная экономика», установлены ее основные функции (социальная, экономическая, общественно-политическая). Основной вывод исследования заключается в том, что социальная экономика занимает определенное пространство между государством (с его защитными механизмами) и рынком (с его экономической эффективностью и сосредоточением на прибыли, основанной на капитале). Чем больше это пространство, тем выше потребность в социальной экономике, способной выполнять задачи, которые не могут быть решены существующей институциональной практикой.

Ключевые слова:

общественная организация, социальное предпринимательство, социальная экономика, социальные услуги, медицинские услуги, образовательные услуги, социально уязвимые группы населения, Болгария.
Terziev Venelin Krastev

D.Sc. (Economics) D.Sc. (National Security), PhD, Professor, Angel Kanchev University of Ruse, Professor, Vasil Levski National Military University, Veliko Tarnovo,

Corresponding Member of the Russian Academy of Natural Sciences

\section{INTERACTION OF SOCIAL ENTERPRISES AND STATE IN BULGARIA}

Summary:

The study considers social enterprises and social entrepreneurship as an example of a sustainable business model driven by both social and economic goals. The research analyzes different types of Bulgarian social enterprises providing social, medical, educational and training services and presents their main characteristics. The concept of social economy is explained, and its basic functions (social, economic, social and political ones) are identified. The author concludes that social economy takes a certain amount of space between the state (with its defense mechanisms) and the market (with its economic efficiency and focus on capital-based profits). The larger is this space, the greater is the need for social economy able to meet the challenges that cannot be addressed by existing institutional practices.

Keywords: public organization, social entrepreneurship, social economy, social services, medical services, educational and training services, vulnerable social groups, Bulgaria.

Социальная экономика - комплексное понятие, в котором основное внимание уделяется прямому социальному эффекту от деятельности предприятия или организации, которые образованы с определенной социальной целью и целенаправленно выполняют свою деятельность для достижения подобного результата. Социальная экономика является одновременно частью реально существующей экономики и гражданского общества, в котором физические или юридические лица, ассоциации добровольцев или другие организованные субъекты осуществляют экономическую деятельность в пользу общества и реинвестируют доход для достижения социальных целей.

Основными функциями социальной экономики являются [1]

1) экономическая - для самообеспечения отрасли ресурсами;

2) социальная - реализуется через профиль затрат;

3) общественно-политическая - формирование установок социальной солидарности

По своей функциональной структуре социальная экономика помогает процессу социального участия и отличается от корпоративного капитализма.

В рамках социальной экономики создается устойчивая бизнес-модель, которая оценивается не по размеру и сорерам деятельности, а по степени уважения общих ценностей, таких как верховенство демократии через обязательное участие в ней субъектов гражданского общества для достижения социального прогресса и охраны прав личности; защита и реализация принципов солидарности и ответственности; сочетание личных интересов участников организации с общественным; демократический контроль со стороны членов организации; добровольное и открытое 
членство; автономия управления и независимость от государственных органов; направление избытка доходов на удовлетворение социально значимых потребностей членов организации для достижения целей стабильного развития.

Развитие социальной экономики обеспечивается посредством кооперативных, частных и коллективных социально-экономических инициатив, основанных на мобилизации и кооперировании ресурсов, доверии и взаимопомощи. Добровольное участие, демократическое и прозрачное управление, коллективное принятие решений по правилу «один человек - один голос» остаются ведущими принципами организаций социальной экономики. В основу трудовой интенсивной технологии на первое место поставлена общественная польза, а не прибыль, предлагаются низкие цены за социально значимые продукты. Социальная экономика способствует повышению жизненных шансов населения и приводит к равномерному распределению национального дохода. Эти социально-экономические инициативы реализованы при участии представителей социально уязвимых групп населения, которые располагают экономической свободой.

Предприятия социальной экономики управляются как предприятия, которые производят товары и услуги для рыночной экономики, и направляют свои ресурсы на достижение социальных и экологических целей [2].

Социальная экономика включает в себя все виды предприятий, независимо от их организационно-правовой формы, созданные и действующие преимущественно для достижения социальных целей. Такими могут быть кооперативы, муниципально-частные партнерства, ассоциации, общества взаимного страхования, фонды и т. п.

Социальная экономика занимает определенное пространство между государством (с его защитными механизмами) и рынком (с его экономической эффективностью и увеличением прибыли на основе капитала). Чем больше это пространство, тем выше потребность в социальной экономике, способной выполнять задачи, которые не могут быть решены существующей институциональной практикой. Социальная экономика служит и как инструмент развития социальных услуг, включая в трудовые отношения группы, находящиеся в неблагоприятном положении; улучшения фрнкциональной системы социальных услуг; развития местной экономики; преодоления бедности и социальной изоляции.

Через развитие сектора социальной экономики расширяются возможности экономического роста территории и увеличения показателя ВВП, повышения уровня занятости и создания условий и благоприятной среды для принятия инновационных социально значимых предпринимательских решений [3].

Институциональный ресурс для обслуживания и развития социальной экономики представляет собой биполярную систему государственных учреждений, которые разрабатывают и используют законодательную базу и меры финансовой поддержки, с одной стороны, и генерируют социальный продукт, кооперативы, предприятия и организации - с другой. Сохраняя автономность в секторе, две стороны процесса не контактируют непосредственно, связь между ними может осуществляться посредством разнообразных по своим статусу и мощности учреждений-посредников.

Принцип институционального взаимодействия состоит в наличии юридической и обратной связи между государством и предприятиями и организациями социальной деятельности. Юридическая связь обеспечивает юридический ресурс и целенаправленные, стимулирующие государственные ресурсы. Обратная связь предполагает предоставление статистических данных в этой области компетентным государственным учреждениям.

Следует повысить роль местных властей в развитии социальной экономики. В настоящий момент их функции недостаточно определены как теоретически, так и практически. Местные власти исследуют и определяют потребности населения, инициируют и поддерживают региональную политику и неофициальные платформы в развитии различных проявлений социальной экономики в локальных территориях.

Ожидается участие муниципальных компаний в создании социальных предприятий на принципах партнерства. Выбор механизмов данного партнерства будет зависеть от возможностей, потребностей и предпочтений местных властей.

В Болгарии существует большое количество предприятий и организаций, которые попадают в сектор социальной экономики: специализированные предприятия, кооперативы людей с ограниченными возможностями, кооперативы, зарегистрированные Законом о кооперативах и несущие ответственность за показатели социальных предприятий, социальные предприятия по отношению к некоммерческим, юридическим лицам (фонды и ассоциации). В развитии сектора определенную роль исполняют неформальные структуры - сети и платформы, работающие над развитием социальной экономики [4].

Сеть взаимных обществ, как правило в предприятиях, имеет свои традиции и в болгарском обществе. Люди в них оказывают друг другу взаимную помощь и в области финансовых услуг, 
например предоставляют мини-кредит, помогают в вопросах здравоохранения и социального обеспечения, страхования. Данные общества тоже могли бы развиваться как социальные предприятия.

В Болгарии имеют место институциональная и нормативная свобода действий, широкие возможности создания и развития социальных предприятий и неформальных сетей в соответствии с действующим законодательством.

Социальные предприятия, предоставляющие социальные услуги

Согласно Закону о социальной помощи, «социальные услуги» - это вид деятельности по предоставлению услуг, которые направлены на поддержку нуждающихся в помощи людей для обеспечения их полноценной жизни.

Существенной частью понятия «социальная услуга» выступает социальная интеграция потребителя, которая должна сопровождать непрерывный процесс предоставления услуг. В связи с этим предоставление оплачиваемых социальных услуг приводит к накоплению доходов от экономической деятельности и в этом смысле является одним из видов социального предпринимательства. Растущая тенденция делегирования государством и особенно муниципалитетами полномочий по предоставлению социальных услуг в последние годы укрепляет эту часть социальных предприятий, будь то коммерческая компания или неправительственная организация.

Поставщики социальных услуг должны пройти обязательную регистрацию в реестре Агентства социальной помощи. Они имеют право:

- подавать заявки на финансирование социальных услуг из государственного бюджета и из муниципальных бюджетов;

- финансировать свою деятельность за счет доходов от платы пользователей за предоставление социальных услуг;

- подавать заявки на получение средств из Фонда социальной помощи (в настоящее время - Фонда социальной защиты) или других государственных фондов, которые фринансируют социальные услуги;

- подавать заявки на проекты, финансируемые в рамках оперативной программы «Развитие человеческих ресурсов»;

- финансироваться другой коммерческой деятельностью торговой компании, если речь идет о такой.

Социальные предприятия, предоставляющие медицинские услуги

Поскольку речь идет о немедицинских заведениях, этот тип социальных предприятий предоставляет базовые (основные) медицинские услуги: измерение артериального давления, помощь медицинских сестер / реабилитаторов, советы по приему лекарств, перевязка, профилактические осмотры и консультации, бесплатные анонимные консультации, тесты на ВИЧ и др.

На практике эти услуги - часть социальных услуг, предоставляемых предприятиями, например домашний социальный патронаж или помощь людям, страдающим зависимостями, женщинам, оказавшимся в трудном положении, и т. д. Данные услуги предоставляются за счет целевого проектного финансирования, осуществляемого муниципальным бюджетом.

Социальные предприятия, предоставляющие образовательные услуги

Закон предоставляет как некоммерческим организациям, так и коммерческим компаниям или кооперативам право на регистрацию и аккредитацию их по установленным правилам как школ или центров профессионального обучения. Они могут выдавать действительные дипломы, подтверждающие получение выпускником соответствующей образовательной или профессиональной квалификации. Социальный аспект этого типа деятельности состоит в найме представителей социально уязвимых групп и людей с особыми потребностями в качестве преподавателей или в организации специальных курсов для них.

Финансирование обучения может осуществляться разными способами: оплата услуг непосредственно обучающимися, на основе проекта, посредством целевых субсидий, предоставляемых государством или муниципалитетом.

Тенденцией последних лет является организация социальных предприятий в сфере производства - в основном малых и средних предприятий, которые производят продукцию легкой и пищевой промышленности, сельскохозяйственную продукцию. В технологически развитых государствах особенно перспективно производство современных технологий, но в Болгарии этот тип деятельности пока развит слабо.

Помимо описанных выше механизмов - финансирования из государственного или муниципального бюджетов, социальные предприятия в Болгарии могут использовать и другие механизмы фринансирования.

Кредитование все еще остается труднодоступным для социальных предприятий. Несмотря на сжатие объемов кредитного рынка Болгарии, в условиях кризиса часть коммерческих банков разрабатывает специальные кредитные продукты для малых и средних предприятий, в том числе для фрермеров. 
Другой доступный механизм частичного финансирования - это доходы от частных пожертвований, осуществляемых благотворительными компаниями.

Наиболее важным механизмом остается предоставление доходов от деятельности по проектам, в которых некоммерческие организации исключительно сильны и активны. В Болгарии основным источником финансирования деятельности НКО являются иностранные фонды. Появление европейских структурных фондов в Болгарии вывело на новый уровень партнерство между НКО и государством в лице Министерства труда и социальной политики и его агентств, а также муниципалитетов. Большая часть средств европейских программ распределяется этими структурами, что потребовало дополнительных усилий для создания эффективных деловых отношений между государственным, муниципальным и некоммерческим секторами. Тем не менее структурные фоонды, несмотря на значительный масштаб их распространения, вряд ли смогут заменить государство и муниципалитеты как источники финансирования социальных предприятий.

Наличие действующей правовой базы для специализированных предприятий для людей с ограниченными возможностями (например, Закона об интеграции людей с инвалидностью) объясняет их массовость, а также в значительной степени перекрытие понятия «специализированное предприятие» термином «социальное предприятие». По существу, социальное предпринимательство в развитых европейских практиках охватывает значительно более широкий круг групп риска. Среди болгарских предприятий также выявлены организации, ориентированные на различные социально уязвимые группы населения. За исключением людей с ограниченными возможностями социальные предприятия Болгарии работают для людей из групп этнического меньшинства, людей, достигших пенсионного возраста, безработных, которые не могут трудоустроиться на протяжении долгого времени, наркоманов, бывших заключенных, детей из интернатов.

О слабом развитии сектора говорит тот факт, что нет данных о наличии рабочих систем мониторинга и оценки социального эффректа, фрункционирующих в исследуемых социальных предприятиях.

Таким образом, группы социальных предприятий, действующие в Болгарии, способствуют расширению предоставления социальных услуг, включению в трудовые отношения представителей социально уязвимых групп населения, в том числе лиц с ограниченными возможностями здоровья, развитию экономики государства и выступают действенным механизмом борьбы с нищетой и социальной изоляцией. Предполагается, что развитие сектора социальной экономики позволит повысить уровень занятости населения и создать благоприятную среду для принятия инновационных социально значимых бизнес-решений.

\section{Ссылки:}

1. Национална концепция за социална икономика. Министерство на труда и социалната политика. София, 2011.

2. Доклад - социални предприятия в България. Проект «Партньорство за социални предприятия в България» [Электронный $\quad$ ресурс]. URL: http://socialenterprise.bg/docs/conference_1/Партньорство\%20за\%20социални\%20предприятия\%20-\%20доклад\%20от\%20изследване.рdf (дата обращения: 12.02.2018).

3. Насърчаване и развитие на социалните предприятия в България - ПъТНА КАРТА (2015-2020) ГЭлектронный ресурс] / Български център за нестопанско право и Фондация Помощ за благотворителността. Проект «Укрепване на Форум “Социални предприятия в България"», финансиран в рамките на Програмата за подкрепа на НПО в България по Финансовия механизъм на Европейското икономическо пространство 2009-2014 гг. URL: http://socialenterprise.bg/events/itemlist/tag/пътна\%20карта.html (дата обращения: 13.02.2018).

4. Куманова М., Шабани Н. Анализ на социалното предприемачество в България [Электронный ресурс] : проект «Инициатива за иновации в социалната икономика» с финансовата подкрепа на Европейския социален фонд и Република България чрез оперативна програма «Развитие на човешките ресурси», схема «Без граници - Компонент 1», изпълняван от Сдружение «Знание» - Ловеч. URL: https://www.ngobg.info/bg/documents/49/1246analiz_inovacii.pdf (дата обращения: 13.02.2018).

\section{References:}

Kumanova, M \& Shabani, N 2018, Analysis of Social Entrepreneurship in Bulgaria: Project Initiative for Innovation in the Social Economy" under the financial support of the European Social Fund and the Republic of Bulgaria through the Operational Program 'Human Resources Development', 'Without Borders - Component1' implemented by Knowledge Association - Lovech, viewed 13 February 2018, <https://www.ngobg.info/bg/documents/49/1246analiz_inovacii.pdf>, (in Bulgarian).

National Concept of Social Economy. Ministry of Labor and Social Policy 2011, Sofia, (in Bulgarian).

Promotion and Development of Social Enterprises in Bulgaria - ROAD CARD (2015-2020) 2018, Bulgarian Center for Notfor-Profit Law and Charity Aid Foundation. Project 'Strengthening the Forum 'Social Enterprises in Bulgaria' funded under the Non-Governmental Organization Support Program in Bulgaria under the Financial Mechanism of the European Economic Area in 2009-2014, viewed 13 February 2018, <http://socialenterprise.bg/events/itemlist/tag/пътна\%20карта.html>, (in Bulgarian).

Report - social enterprises in Bulgaria. Project 'Partnership for Social Enterprises in Bulgaria' 2018, viewed 12 February 2018, <http://socialenterprise.bg/docs/conference_1/Партньорство\%203а\%20социални\%20предприятия\%20\%20доклад\%20от\%20изследване.pdf>, (in Bulgarian). 